\title{
Identidades de raça/etnia, ensino crítico e o racismo no livro de inglês aprovado pelo PNLD
}

\section{Identities of race/ethnicity, critical teaching and racism in the english textbook approved by the PNLD}

\section{Luís Frederico Dornelas CONTI* \\ SEEDF \\ Mariana Rosa MASTRELLA-DE-ANDRADE ${ }^{* *}$ \\ $U n B$}

Resumo: O racismo no Brasil, encoberto pelo mito da democracia racial com que vivemos (BERNARDINO, 2002; CARNEIRO, 2002; FERREIRA, 2007), e suas consequências nefastas, é a dura realidade com que lutam diariamente os negros neste país. Apesar das vitórias conquistadas nos últimos anos, muito ainda tem de ser feito e discutido. Considerando-se que a escola não pode jamais ser tomada como uma entidade politicamente neutra (PENNYCOOK, 1999, 2001), e que, nas nossas práticas discursivas, dentro e fora da sala de aula, produzimos e mantemos identidades (MASTRELLA-DE-ANDRADE, 2013; WOODWARD, 2000) e legitimamos injustiças, é necessário que reflitamos criticamente sobre as práticas pedagógicas e recursos didáticos que utilizamos em nossas aulas. Desta forma, a exemplo de investigações anteriores (CAMARGO e FERREIRA, 2014a), pretende-se com este trabalho questionar se a série Vontade de Saber Inglês, aprovada pelo Programa Nacional do Livro Didático para o triênio 2014-2016, facilita as discussões em sala de aula sobre História e Cultura Afro-Brasileira, como estabelecem as Leis Federais 10.639/03 e 11.645/08. As análises aqui empreendidas apontam para a permanência do que pode ser chamado de racismo velado: a invisibilidade dos negros, discursos liberais sobre a diversidade e a fuga constante a questões que encarem a realidade do racismo em nosso país.

Palavras-chave: Racismo. Mito da democracia racial. Identidade. Livro didático. Ensino crítico de línguas.

\begin{abstract}
Racism in Brazil is veiled by the myth of racial democracy (BERNARDINO, 2002; CARNEIRO, 2002; FERREIRA, 2007). The terrible consequences of racism are the painful reality that black people encounter on a daily basis in Brazil. In spite of victories that have been won in recent years, much still has to be done and discussed. Considering that the school environment can never be seen as politically neutral (PENNYCOOK, 1999, 2001), and that through their discursive practices inside and outside the classroom, teachers produce and maintain identities (MASTRELLA-DE-ANDRADE, 2013; WOODWARD, 2000) and legitimate injustices, it is crucial for teachers to critically reflect on their
\end{abstract}

* Professor de Língua Estrangeira Moderna - Inglês, pela Secretaria de Estado de Educação do Distrito Federal (SEEDF). E-mail: luisfdconti@gmail. com.

** Professora adjunta do Departamento de Línguas Estrangeiras e Tradução da Universidade de Brasília (UnB). E-mail: marianamastrella@ gmail.com. 
pedagogical practices and the resources that they use in class. Thus, following the example of previous studies (CAMARGO and FERREIRA, 2014a), this article questions whether the series of books entitled Vontade de Saber Inglês (The Desire to Speak English), which was approved by the Programa Nacional do Livro Didático (National Policy for Textbooks) for the period 2014-2016 facilitates debates about Afro-Brazilian history and culture in the classroom, as was made obligatory by Federal Laws 10.639/03 and 11.645/08. The analysis in this article demonstrates that covert racism, the invisibility of black people, liberal discourses about diversity, and the constant evasion of a proper discussion of the reality of racism in Brazil, still remain.

Keywords: Racism. Myth of racial democracy. Identity. Textbook. Critical language teaching.

\section{Introdução}

Em sua síntese da situação do ensino de língua estrangeira no Brasil, os Parâmetros Curriculares Nacionais (PCNs) apontam para diversas dificuldades enfrentadas diariamente por professores que ensinam essa disciplina na escola pública: "falta de materiais adequados, classes excessivamente numerosas, número reduzido de aulas por semana, tempo insuficiente dedicado à matéria no currículo e ausência de ações formativas contínuas junto ao corpo docente” (BRASIL, 1998, p. 24). Tendo em vista que mesmo um dos textos basilares nas discussões sobre as práticas pedagógicas em escolas brasileiras reconhece a escassez de recursos com a qual professores têm de lidar nesse contexto, que em decorrência desse desafio constante o livro didático estabelece-se como "o instrumento básico, e muitas vezes o único, de trabalho do professor de língua estrangeira da escola pública” (CAMARGO e FERREIRA, 2014a, p. 178), e que estudos recentes (CAVALLEIRO, 2000; FERREIRA, 2007, CAMARGO e FERREIRA, 2014a, 2014b; GUIMARÃES, 1995; KUBOTA, 2013; PESSOA, 2014) nas áreas de ensino de línguas e de linguística aplicada têm tido um papel crucial na constatação e na desconstrução do mito da democracia racial no Brasil, este artigo vem questionar se o livro didático de língua inglesa como língua estrangeira usado na escola pública no Brasil oferece os meios necessários para facilitar discussões sobre História e Cultura Afro-Brasileira na sala de aula, como estabelecem as Leis Federais 10.639 de 09/01/2003 e 11.645 de 10/03/2008.

Os livros analisados foram os da série Vontade de Saber Inglês, para o sexto, sétimo, oitavo e nono anos do Ensino Fundamental, aprovados pelo Programa Nacional do Livro Didático (PNLD) para o triênio 2014-2016. Os dados analisados mostraram que o debate crítico sobre a desigualdade entre raças/etnias (cf. Fundamentação Teórica) continua sendo um trabalho 
árduo para professores de língua inglesa que, no contexto das escolas públicas, têm acesso a uma quantidade extremamente limitada de materiais. Isso ocorre porque os livros analisados, como demonstraremos adiante (cf. Análise dos Dados), além de darem pouquíssima visibilidade a negros e pessoas de outras raças/etnias que não a branca e de se inscreverem no que vem se chamando multiculturalismo liberal (KUBOTA, 2004, 2013), não discutem, de nenhuma forma, História e Cultura Afro-Brasileira.

Autores como Luke (1997), Norton (2013) e Pennycook (2001) sugerem que o interesse por identidade representa uma mudança de foco, de uma perspectiva micro para uma perspectiva macro, nas pesquisas em letramento e ensino e aprendizagem de línguas. Tal mudança de perspectiva "tem sido relacionada a análises sociológicas do papel da escola na reprodução do poder, conhecimento e acesso a recursos materiais de uma geração à outra”" (LUKE, 1997, p. 143). Como Norton (2013) reitera, “os pesquisadores interessados em identidade e aprendizagem de línguas não estão preocupados somente com input e output linguístico na $\mathrm{ASL}^{2}$, mas também com o relacionamento entre aprendiz de língua e o mundo externo" (p. 90). Pennycook (2001) afirma que "olharmos para identidade como algo que realizamos através da língua, ao invés de refletida na língua, nos ajuda a escaparmos das identidades essencializadas em muitos trabalhos na linguística aplicada”3 (p. 162). Faz-se necessário, assim, que uma crítica dos materiais didáticos usados na sala de aula leve em consideração as desigualdades reproduzidas tanto dentro como fora dela.

Lançando um olhar sobre os novos e velhos desafios do Movimento Negro no Brasil, Carneiro (2002) ressalta a manutenção de estereótipos racistas em livros didáticos e a invisibilidade de negros, da história dos povos africanos e da cultura afro-brasileira nos currículos escolares. Explorando, então, no mesmo texto, as potencialidades de organização política dos negros, a autora expõe que "Os brancos revisitam os seus clássicos, especialmente nos momentos de crise. As novas gerações de militantes negros sequer conhecem os nossos, pois não criamos meios de transmitir nosso patrimônio libertário" (p. 214), e indaga: "Se não é a nossa história de lutas, quem, ou o que informa hoje a nossa prática política?” (p. 214). A escola e os professores devem, portanto, assumir seu papel crítico nessa luta (FERREIRA, 2012) e é a partir deste convite que este artigo se debruça sobre os livros referidos acima.

Tendo em vista esse objetivo, na seção a seguir trazemos nossa fundamentação teórica, na qual apresentamos e discutimos algumas questões relacionadas à maneira como pontos fundamentais do trabalho são compreendidos. Depois, na seção sobre a metodologia da pesquisa, apresentamos os livros didáticos aqui analisados, bem como a perspectiva interpretativista de pesquisa (MOITA LOPES, 1994), que guia nossas análises dos dados na parte seguinte.
${ }^{1}$ Tradução nossa. Original: "[Such a change in foundational perspective] has been linked to sociological analyses of the role of schooling in the intergenerational reproduction of power, knowledge, and access to material resources."

${ }^{2}$ Aquisição de Segunda Língua.

${ }^{3}$ Tradução nossa. Original: "Looking at identity as something we perform through language rather than something reflected in language helps get away from the essentialized identities of much applied linguistic work." 


\section{Fundamentação Teórica}

\section{O mito da democracia racial no Brasil}

Nos últimos anos, o Movimento Negro no Brasil tem conquistado diversas vitórias, tais como: a criação de "campanhas de ação afirmativa para que os negros possam se sentir orgulhosos de sua cor e de sua ascendência” (FERREIRA, 2012, p. 196) e das "cotas nas universidades, [...]” que resultaram “em um acalorado debate sobre a questão [...], trazendo possibilidades de pensarmos uma sociedade mais justa e igualitária para o Brasil” (FERREIRA, 2012, p. 197); a criação das Leis Federais 10.639/03 e 11.645/08, que tornam obrigatório, nos "estabelecimentos de ensino fundamental e médio, oficiais e particulares", o ensino sobre a "História da África e dos Africanos, a luta dos negros no Brasil, a cultura negra brasileira e o negro na formação da sociedade nacional, resgatando a contribuição do povo negro nas áreas social, econômica e política pertinentes à História do Brasil [...] no âmbito de todo o currículo escolar” (BRASIL, 2003); e a criação, pelas universidades, dos NEABs (Núcleos de Estudos Afro-Brasileiros), que, em 2012, já eram mais de 70 (FERREIRA, 2012).

Apesar disso, muito ainda tem que ser feito e discutido. Autores como Bernardino (2002), Carneiro (2002) e Rosemberg, Bazilli e Silva (2003) denunciam que nós vivemos no Brasil o mito da democracia racial. De acordo com Bernardino (2002):

Para os que imaginam e advogam a singularidade paradisíaca brasileira, isto significa dizer que o critério racial jamais foi relevante para definir as chances de qualquer pessoa no Brasil. Em outras palavras, ainda é fortemente difundida no Brasil a crença de que a cultura brasileira antecipa a possibilidade de um mundo sem raças. (p. 249).

Rosemberg, Bazilli e Silva (2003) explicam que preferem o termo mito a ideologia, "pois reserva[m] este último à conceituação do racismo, sendo o mito da democracia racial apenas um modo de operação da ideologia racista” (p. 128). Carneiro (2002), contudo, em sua crítica à organização política do Movimento Negro no Brasil, defende o uso da expressão neo-democracia racial. Esta, segundo a autora, "estabelece a capacidade de consumo como o limite da cidadania negra [...] enquanto, por outro lado, ampliam-se os mecanismos de exclusão social da maioria” (p. 212) e atende a pelo menos dois interesses:

O primeiro, de ordem política, visa amortizar a crescente tomada de consciência e a capacidade reinvidicatória dos afro-descendentes, especialmente o segmento mais jovem, assim impedindo que o conflito racial se explicite com toda a radicalidade necessária para promover a mudança social. O segundo interesse, de ordem econômica, é determinado pela lógica de mercado estabelecida pelo capitalismo globalizado, ávido por novos mercados, 
o qual antevê, na potencial consolidação de uma classe média negra, a viabilização de um novo mercado consumidor. (p. 212).

Faz-se necessário, neste ponto, que se demonstre por que falamos em um mito da democracia racial no Brasil. Voltemo-nos então para alguns números relativos ao racismo neste país. Segundo dados do Instituto Brasileiro de Geografia e Estatística (IBGE):

[...] trabalhadores de cor preta ou parda ganhavam, em média, em 2013, pouco mais da metade $(57,4 \%)$ do rendimento recebido pelos trabalhadores de cor branca - as médias anuais do rendimento foram de $\mathrm{R} \$ 1.374,79$ para os trabalhadores de cor preta ou parda, enquanto a dos trabalhadores de cor branca foi de R \$ 2.396,74. Em 2012, esta razão era 56,1\% e, em 2003, não chegava à metade (48,4\%). (IBGE, 2014). ${ }^{4}$

Além disso, não é difícil encontrar em páginas de notícias online artigos que digam, por exemplo: “Aumenta o número de denúncias de injúria racial e racismo: nos últimos três anos, as denúncias oferecidas pelo Ministério Público do Distrito Federal e Territórios aumentaram 330\%”;; “A cada 60 horas, uma ocorrência de racismo é registrada em Minas Gerais: foram 147 ocorrências de racismo em 2013, mas números são subnotificados";; ou "Denúncias de racismo no Brasil dobraram nos últimos anos: em 2011, a Secretaria de Igualdade Racial registrou 219 denúncias, em 2013 foram 425"7. Apesar disso, um estudo realizado pelo Laboratório de Análises Econômicas, Sociais e Estatísticas das Relações Raciais (Laeser), da Universidade Federal do Rio de Janeiro, em 2011, “analisou julgamentos em segunda instância de crimes de racismo e injúria racial nos tribunais de todo os estados brasileiros, entre 2007 e 2008 [...] [e] constatou que 70\% das 148 ações impetradas na época acabaram sendo vencidas pelos réus”. O então presidente da Comissão da Igualdade Racial da OAB/SP, Eduardo Pereira da Silva, em entrevista à mesma revista na mesma reportagem, notou que "há uma enorme dificuldade de provar o crime racial" e que "esse receio existe porque essas ocorrências seriam, em maioria, embates entre classes mais abastadas e pessoas de menor poder aquisitivo”.

Uma das consequências é a violência exacerbada que sofre a população negra no Brasil. Cerqueira e Moura (2013), em um relatório feito a pedido do Instituto de Pesquisa Econômica e Aplicada (IPEA), baseando-se em dados do SIM/MS/SVS/Dasis e do Censo Demográfico do IBGE de 2010, apontam que "para cada homicídio de não negro no Brasil, 2,4 negros são assassinados, em média” (p. 3). Em entrevista ao Instituto Humanitas Unisinos (IHU), Rodrigo Leandro de Moura, um dos autores do estudo, afirma que $20 \%$ das causas desses homicídios são associadas a questões socioeconômicas, e os outros $80 \%$ a outras formas de racismo, como "a discriminação no mercado de trabalho, [...] a desigualdade de
${ }^{4}$ IBGE. Instituto Brasileiro de Geografia e Estatística. Desocupação foi de $4,3 \%$ em dezembro e fecha 2013 com média de 5,4\%. Disponível em: http:// saladeimprensa.ibge.gov. $\mathrm{br} /$ noticias?view $=$ noticia\&id $=1 \&$ busca $=1 \&$ id noticia $=2575$. Acesso em: 13/07/15. 2014.

${ }^{5}$ PORTAL DO MPDFT. Dia da Consciência Negra: aumenta o número de denúncias de injúria racial e racismo. Disponível em: http:// www.mpdft.mp.br/portal/ index.php/comunicacaomenu/noticias/ noticias-2013/6536dia-da-consciencianegra-aumenta-o-numerode-denuncias-de-injuriaracial-e-racismo. Acesso em: 13/07/15. 2013.

${ }^{6}$ JORNAL DO ESTADO DE MINAS. A cada 60 horas, uma ocorrência de racismo é registrada em Minas Gerais. Disponível em: http://www.

em.com.br/app/noticia/ gerais/2014/02/15/interna_ gerais,498605/a-cada-60horas-uma-ocorrencia-deracismo-e-registrada-emminas-gerais.shtml. Acesso em: 13/07/15. 2014.

${ }^{7}$ PORTAL R7 NOTÍCIAS. Denúncias de racismo no Brasil dobraram nos últimos anos. Disponível em: http://noticias. r7.com/brasil/denunciasde-racismo-no-brasildobraram-nos-ultimosanos-30082014. Acesso em: 13/07/15. 2014.

${ }^{8}$ REVISTA RAÇA BRASIL. Racismo: o ciclo da impunidade. Disponível em: http://racabrasil.uol. com.br/cultura-gente/156/ racismo-o-ciclo-daimpunidade-pesquisarevela-que-70-224060-1. asp. Acesso em: 13/07/15. 2011. 
oportunidades e [...] os estereótipos negativos que acabam afetando a autoestima de crianças e jovens negros"

\section{Raça/etnia, identidade e ensino crítico}

Neste trabalho, etnia refere-se a "grupos que dividem a mesma identidade cultural, como língua, religião e história”. (FERREIRA, 2006, apud FERREIRA, 2012). Raça, por sua vez, é entendida como um conceito sócio-histórico e ideologicamente construído. (FERREIRA, 2012; GILLBORN, 1995). Miles (2001) esclarece:

[...] a significação de características fenotípicas para classificar seres humanos em grupos, simultaneamente designadas como naturais [...] começou [na Europa] no século XVIII [...]. Certos traços somáticos (alguns reais e alguns imaginados) foram significados socialmente como marcas de diferença (por exemplo, a cor da pele), uma diferença que se tornou conhecida como uma diferença de 'raça'. Além disso, acreditou-se que essas marcas, concebidas como naturais, explicavam a já existente posição social da coletividade designada pela marca. Este processo social de significação foi (e continua sendo) um importante momento ideológico em um processo de dominação. A ideia de 'raça' veio assim a exprimir natureza, algo dado e imutável, resultando em que o que era, na verdade, consequência de relações sociais tornou-se entendido como natural: e então pensou-se 'raça' como uma força determinada, necessitando relações sociais de dominação para ser organizada de um modo específico, destarte obscurecendo sua construção humana ${ }^{10}$ (p. 137).

A perspectiva com a qual Miles (2001) vê o construto de raça é congruente com o entendimento que pensadores como Leffa (2012), Mastrella-de-Andrade (2013), Norton (2000) e Woodward (2000) têm de como acontece a construção de identidades. De forma análoga à referência que Miles (2001) faz às marcas de diferença pelas quais a ideia de raça é concebida, Leffa (2012) atribui a criação das identidades a "certas características que abstraímos de objetos e pessoas”, isto é, a "traços, muitas vezes aleatórios” (p. 55; grifo nosso). Alertando-nos sobre o perigo da forma arbitrária com que essa abstração dos traços identitários muitas vezes é feita, conclui: “[...] é exatamente isso que acontece quando pegamos a cor da pele, a forma do crânio ou a espessura dos lábios para qualificar - ou desqualificar - as pessoas de uma comunidade” (p. 56).

Mastrella-de-Andrade (2013, p. 37) também articula identidade e diferença, reiterando que ambas são definidas “numa produção simbólica e discursiva, por meio de um processo linguístico contínuo de diferenciação e diferimento, adiamento, que se dá socialmente, por meio das relações e interações”. E, reconhecendo as relações assimétricas em que essa produção se dá, assevera:

[...] a definição da identidade e da diferença nunca é uma prática inocente, objetiva ou imparcial. Ao contrário, está sempre ligada a disputas e embates,
${ }^{9}$ IHU. Instituto Humanitas Unisinos. Racismo explica $80 \%$ das causas de morte de negros no país. Entrevista especial com Rodrigo Leandro de Moura. Disponível em: http://www.ihu.unisinos. br/entrevistas/526138racismo-explica-80-dascausas-de-morte-denegros-no-pais-entrevistaespecial-com-rodrigoleandro-de-moura. Acesso em: 13/07/15. 2013.

${ }^{10}$ Tradução nossa. Original: “[...] the signification of phenotypical features in order to classify human beings into groups [...] began [in Europe] in the eighteenth century ]...]. Certain somatic features (some real and some imagined) were socially signified as natural marks of difference (e.g. skin colour), a difference that became known as a difference of 'race'. Moreover, these marks, conceived as natural, were then thought to explain the already existing social position of the collectivity thereby designated by the mark. This social process of signification was (and remains) an important ideological moment in a process of domination. The idea of 'race' thereby came to express nature, something given and immutable, with the result that what was in fact the consequence of social relations became understood as natural: and so 'race' was thought of as a determinate force, requiring social relations of domination to be organised in a specific form, thereby obscuring their human construction." 
choques e conflitos de interesse, poder e legitimação de verdades. O próprio fato de haver diferença, enquanto processo definidor da identidade e da própria diferença, já se relaciona com a questão do poder - é ele, o poder, que a permite e impõe. (p. 38).

Estabelecendo uma conexão direta entre identidade, poder e acesso a recursos simbólicos e materiais, Norton (2000, p. 8) afirma que "a questão 'Quem sou eu?' não pode ser entendida à parte da questão 'O que posso fazer?', e a questão 'O que posso fazer?’ não pode ser entendida à parte das condições materiais que estruturam oportunidades para a realização de desejos" "11. Essa forma de pensar a relação intrínseca que a construção de identidades e negociações de poder têm ecoa a compreensão de Woodward (2000, p. 17), quando, voltando-se para as práticas de significação e os sistemas de representação que produzem, afirma que estas "fornecem possíveis respostas às questões Quem eu sou? O que eu poderia ser? Quem eu quero ser?”. Tomando, portanto, as práticas de significação (dentro e fora da escola) como embebidas em disputas de poder e como produtoras de identidades, devemos nos perguntar: "como educadores de línguas e letramento [...], quais práticas pedagógicas ajudarão os aprendizes a desenvolver a capacidade de imaginar uma gama de identidades para o futuro" (NORTON, 2013, p. 104), ou, em conformidade com o que advogam outros autores da área de ensino e letramento crítico (FREIRE, 1975; PESSOA e URZÊDA-FREITAS, 2012, PENNYCOOK, 1999, 2001), como:

[...] desenvolver uma forma crítica de pedagogia que discute as marginalizações e exclusões da educação, motivando alunos a desenvolver suas próprias vozes. Voz [...] [como] uma compreensão mais ampla da criação de possibilidades para articular realidades alternativas. ${ }^{12}$ (PENNYCOOK, 2001, p. 130; grifo nosso).

Baseando-se na perspectiva foucaultiana de poder disciplinar e em sua crítica às instituições que o usam para vigiar, punir e manter o status quo, como hospitais, hospícios, prisões e igrejas, Mastrella (2007, p. 73) chama-nos a atenção para como também a educação se constitui como uma prática disciplinar de normalização e de controle social. Assim, sendo "nas práticas educacionais (...) que encontramos as primeiras e definitivas 'verdades' sobre quem somos, quem podemos ser e o que podemos fazer", e o livro didático um "artefato de currículo” (APPLE, 1995, apud SILVA, TEIXEIRA e PACÍFICO, 2014), é imprescindível que uma análise crítica dos seus conteúdos seja feita no intuito de questionar se estereótipos e imagens negativas sobre negros são reproduzidos e se discussões sobre História e Cultura Afro-Brasileira (em cumprimento das leis supracitadas) são efetuadas ou não (CAMARGO e FERREIRA, 2014a, 2014b). Na próxima seção será feita uma breve descrição do objeto que este trabalho investiga,
${ }^{11}$ Tradução nossa. Original: "[Thus] the question 'Who am I?' cannot be understood apart from the question 'What am I allowed to do?' And the question 'What am I allowed to do?' cannot be understood apart from material conditions that structure opportunities for the realization of desires.”

12 Tradução nossa. Original: “[...] [one can start] to develop a critical form of pedagogy that addresses the marginalizations of exclusions of schooling by encouraging students to develop their own voice. Voice [...] [as] a broader understanding of developing the possibilities to articulate alternative realities.” 
da orientação metodológica com a qual ele foi realizado e de como ela foi empregada.

\section{Metodologia}

Foram analisados para este artigo os quatro volumes da série Vontade de Saber Inglês, de autoria de Mariana Killner e Rosana Amancio. Os livros foram aprovados pelo PNLD para o triênio 2014-2016, e foram escritos para alunos (e professores) dos chamados anos finais do Ensino Fundamental, isto é, sexto, sétimo, oitavo e nono anos. Vale notar que, no Distrito Federal, uma das unidades federativas do Brasil onde estes livros foram distribuídos, os alunos das escolas públicas nestas quatro séries têm de 10 a 17 anos, e quando ingressam no sexto ano do Ensino Fundamental têm, em sua educação formal e regular, o seu primeiro contato com uma língua estrangeira.

Esta é uma pequisa de cunho qualitativo. Segundo Godoy (1995, p. 63), "quando a nossa preocupação for a compreensão da teia de relações sociais e culturais que se estabelecem no interior das organizações, o trabalho qualitativo pode oferecer interessantes e relevantes dados”. A análise que aqui se realiza foi orientada pela ótica da pesquisa interpretativista (MOITA LOPES, 1994) e da linguística aplicada crítica (PENNYCOOK, 2001).

Baseando-se na crítica ao modo positivista de se fazer ciência em Hughes (1990), Moita Lopes (1994, p. 331) afirma que a pesquisa interpretativista é "um modo de fazer ciência mais adequado aos dados com que nos deparamos em $\mathrm{LA}^{13}$ ou de dar conta do fato de que a linguagem é, ao mesmo tempo, condição para construção do mundo social e caminho para encontrar soluções para compreendê-lo”, isto é, sendo significados construídos por pessoas e para pessoas, que interpretam e reinterpretam o mundo que as rodeiam, "não [há, assim,] uma realidade única, mas várias realidades” (p. 331). Quanto aos requisitos para que uma pesquisa se insira na linguística aplicada crítica, segundo Pennycook (2001, p. 161), quatro critérios básicos devem ser observados: "um modo de trabalhar que se oponha a categorias essencialistas e tente se engajar seriamente com as diferenças; a inclusão dos interesses, desejos e vidas dos participantes; um foco nos mecanismos do poder; e uma orientação a fins transformativos” ${ }^{14}$. Buscamos nos orientar por esses requisitos na condução de nossas análises, as quais apresentamos a seguir.

\section{Análise de dados}

A começar pelas pistas não-verbais que encontramos nos livros, ao olharmos para as quatro capas, é possível observar que houve uma preo-

\section{${ }^{13}$ Linguística Aplicada.}

\footnotetext{
${ }^{14}$ Tradução nossa. Original: "a mode of working that opposes essentialist categories and attempts to engage seriously with differences; the discussion of participants' interests, desires and lives; a focus on the workings of power; and an orientation towards transformative goals."
} 
cupação em retratar um certo nível de diversidade étnico-racial na escolha dos personagens que ali aparecem: quatro crianças, uma em cada capa, olhando para frente e para cima em direção ao título e talvez às gravuras escolhidas como símbolos representantes das culturas anglófonas. Estas (retratos dos rostos de Shakespeare, de Jack Haley como Homem de Lata no filme O Mágico de Oz (1939), de John Lennon e da Estátua da Liberdade), por sua vez, se repetem nas quatro capas. O posicionamento das imagens sugere que as crianças estão com vontade de aprender inglês - título dos livros - e, talvez, vislumbrando as possibilidades que o aprendizado desta língua pode trazer para seus futuros. Apesar da escolha de uma menina negra para a capa do livro do sexto ano, a escolha de três homens brancos, dois ingleses e um norte-americano, e um monumento nova iorquino para representar as culturas anglófonas exprime, desde já, que os livros partirão dos pressupostos não somente de que esta língua é falada apenas nos Estados Unidos e Inglaterra, como também de que ela se impõe como capital cultural e simbólico (BOURDIEU, 1991) de homens brancos destes dois países. Ignora-se, assim, que o inglês é falado oficialmente em outros 65 países, 19 dos quais pertencem ao continente africano. Esta ideologia sobre a língua inglesa permeia os quatro livros.

Ainda a respeito das produções artísticas e culturais que aparecem nos livros, observa-se que quase nenhuma visibilidade, se alguma, é dada às culturas de povos afrodescendentes. Na Unidade 6 do livro do sétimo ano, por exemplo, sobre filmes e gêneros cinematográficos, 15 filmes são divulgados, dos quais 14 mostram protagonistas brancos em seus pôsteres. Ao longo da Unidade 1 do mesmo volume, em que se discutem livros, gêneros literários e o hábito da leitura, veem-se capas de livros de 27 autores diferentes. Todos autores brancos e de países tidos como desenvolvidos. Na primeira página desta unidade uma gravura do quadro Mulher Lendo, de Renoir, mostra uma jovem mulher branca segurando um livro. A Unidade 2 do livro do oitavo ano foca em obras de arte consideradas importantes e, em sua primeira página, quatro museus aparecem - três em cidades do continente europeu e um em Nova Iorque. Em seguida, também ao longo desta unidade, 21 obras, entre quadros, desenhos e a fachada de um edifício, são mostradas. Destas, 20 de artistas brancos e 16, dentre elas, de europeus. O que podemos entender desse modo de organizar o livro didático é que não há espaço para a história e as culturas de povos afrodescendentes, o que, além de descumprir o que determinam as Leis Federais 10.639/03 e 11.645/08, anteriormente mencionadas, ilustra bem o que diz Carneiro (2002) sobre a invisibilidade de negros e da história dos povos africanos e da cultura afro-brasileira nos currículos escolares.

Para uma maior exposição da dimensão que tem a invisibilidade de negros nos livros em comparação a brancos, a exemplo de Camargo e Ferreira (2014a, 2014b), contamos os personagens que mostram as figuras dos quatro livros. Foi contabilizado um total de 1.377, excluindo aqueles 
cuja etnia/raça não se podia distinguir (por não serem humanos ou por estarem cobertos, de costas e/ou muito pequenos, em fotos de multidões). Destes, 1.062 (77,1\%) eram brancos, contra apenas 198 (14,3\%) personagens negros. Os demais foram categorizados como pertencentes a outras etnias (indígenas, asiáticos, etc.). Vê-se que os números referentes à visibilidade de afrodescendentes no livro analisado em Camargo e Ferreira (2014a, 2014b) não são muito diferentes dos da série Vontade de Saber Inglês, o que remete ao que as autoras chamam, baseando-se em Apple (2001), de "branquitude como norma”.

Considerando que a prática crítica de ensino deve lançar um olhar cético justamente sobre tudo o que se naturaliza, o que não mais se questiona e o que se estabelece como norma (PENNYCOOK, 1999), perguntamonos então se os livros analisados facilitam, se algum modo, o debate sobre as desigualdades raciais no Brasil e no mundo, e se em algum momento qualquer referência é feita à história dos povos afrodescendentes, de sua participação na construção da nação brasileira (ou em outros países das Américas e Caribe) e de sua luta, desde a colonização destes países até hoje, por direitos iguais. Os resultados mostram que em nenhuma das 32 unidades que compõem os livros estes assuntos são abordados. Mais do que isso, perde-se a oportunidade de discutir racismo e segregação racial em duas das unidades que mais se aproximam do tema da diversidade, consequentemente reforçando-se imagens estereotipadas sobre as etnias/ raças nelas representadas. Estas são a Unidade 2 do livro do sétimo ano, que fala sobre feriados e datas comemorativas ao redor do mundo e os meses do ano, e a Unidade 4 do último livro, sobre o respeito à diversidade.

A primeira inscreve-se na descrição que Kubota (2013, p. 132) faz do que chama de multiculturalismo liberal, uma prática discursiva que "celebra características superficiais de culturas diferentes, enquanto paradoxalmente enfatiza o que a raça humana tem em comum”"15, além de “[tender] a essencializar a cultura no tempo e no espaço, desprezando a vasta diversidade e fluidez dentro das culturas”16 (p. 132). Kubota (2013) relaciona o multiculturalismo liberal ao mito da democracia racial e à falácia da meritocracia. A visão estática das culturas de origem mulçumana, nipônica, hispânica e anglo-saxônica representadas nas imagens deste capítulo não alude aos embates e negociações de poder em que seus membros estão envolvidos. Já a segunda rejeita completamente qualquer abordagem direta às injustiças sociais em que estão inseridos os grupos étnico-raciais minoritários nela presentes. O título da unidade, "Respect everybody", sugere que toda e qualquer pessoa, independentemente de quais sejam suas origens étnico/raciais, sofre, em níveis equiparáveis, exclusões sociais e merecem, portanto, a mesma atenção. Personagens brancos misturados aos de outras etnias/raças reforçam essa impressão. Em um pequeno texto mais adiante na mesma unidade, intitulado "Diversity and inclusion”, uma referência à Declaração Universal dos Direitos Humanos é feita, dizendo
15 Tradução nossa. Original: "[Liberal multiculturalism] celebrates superficial features of cultural differences, while paradoxically emphasizing the commonness of the human race.”

${ }^{16}$ Tradução nossa. Original: "[In celebrating cultural differences, liberal multiculturalism also tends] to essentialize culture in space and time, ignoring the vast diversity and fluidity within cultures.” 
que "não se deve haver discriminação baseada em raça, cor, sexo, língua, nacionalidade, política ou qualquer outra razão”, mas, no mesmo texto, o argumento apresentado para isso é o de que o mundo sem a diversidade não seria "divertido", que ela nos ajuda a construir um mundo "mais completo”, e não que pessoas sofrem cotidianamente as consequências dessas discriminações. Em uma das atividades sobre este texto, diferentes conceitos são apresentados, tais como bullying, respeito, violência, preconceito, discriminação, cidadania, estereótipo e diversidade. Não há, nessa lista, referência ao racismo, isto é, à maneira específica como negros podem ser vítimas de desrespeito e violência na vida social. Novamente, concordamos com Carneiro (2002) quanto ao apagamento de questões mais relacionadas à luta dos negros na sociedade, o que impede que a escola ofereça espaço para que as questões raciais estejam em seu currículo.

Uma das atividades seguintes, na mesma unidade, sobre testemunhos de alunos que sofreram bullying, inclui possibilidades de se trabalhar o preconceito linguístico e até a discriminação de alunos indígenas na escola, mas novamente não menciona o racismo. De igual forma, uma atividade de escuta no mesmo capítulo inclui um personagem negro, mas o único preconceito que relata é o bullying por causa de seu nome. A fuga ao termo racismo nestas atividades reforça mais uma vez a nossa compreensão de que o discurso liberal e, com ele, o racismo velado prevalecem nos livros analisados.

Os resultados das perguntas feitas sobre os livros da série Vontade de Aprender Inglês não diferem largamente do que vem sido demonstrado em pesquisas anteriores relacionando racismo e livro didático. (CAMARGO e FERREIRA, 2014a, 2014b). Considerando que o livro didático tem o potencial para ser um instrumento reprodutor de discursos racistas e essencialistas sobre identidades étnicas e raciais, como já discutimos desde o início neste trabalho, apontaremos na conclusão que segue algumas fontes de inspirações existentes na literatura para atividades críticas na sala de aula, além de nela fazermos as considerações finais sobre o estudo que realizamos.

\section{Conclusão}

O Movimento Negro no Brasil tem conquistado nos últimos anos várias vitórias, avançando significativamente no combate ao racismo do ponto de vista legal (CARNEIRO, 2002), contribuindo, com campanhas de ação afirmativa e discussões em universidades, para que negros possam ter orgulho de sua cor e ascendência (FERREIRA, 2012), e introduzindo novos temas na agenda do movimento, como o enegrecimento das bandeiras feministas (CARNEIRO, 2002), por exemplo. Entretanto, como estas autoras e muitos outros (APPLE, 2001; BERNARDINO, 2002; 
CAVALLEIRO, 2000; CERQUEIRA e MOURA, 2013; GUIMARÃES, 1995; PESSOA, 2014), além de números recentes, como os apontados aqui, demonstram, a exclusão racial, as injustiças em quase todos os âmbitos sociais, as práticas discriminatórias e a violência motivadas por racismo são uma realidade que negros de todo o Brasil enfrentam constantemente.

Considerando que a escola e a sala de aula nunca podem ser politicamente neutras, e são sempre permeadas por disputas por poder (PENNYCOOK, 2001), injustiças sociais e pelo racismo, professores devem agir de forma crítica para a conscientização de seus alunos (FREIRE, 1975) e proporcionar debates que problematizem essas questões, colocando-se contra a reprodução dessas injustiças. Uma reflexão crítica sobre suas práticas pedagógicas e os recursos didáticos de que lançam mão faz-se imperiosa. Isso envolve, inclusive, a consciência de que o binarismo opressor-oprimido pode também acabar servindo para essencializar identidades e de que não existe uma resposta simples para esses problemas. Daí a importância da problematização constante de normas e fatos dados como naturais.

Neste processo, o livro didático, quando usado, deve receber também o mesmo olhar cético. Como demonstramos nesta pesquisa, a invisibilidade dos negros, os discursos liberais sobre a diversidade e a fuga a questões sobre o racismo são lugar-comum nos livros de inglês como língua estrangeira. Se não questionados, eles podem contribuir para a reprodução do status quo. Trabalhos como os de Ferreira (2012), Kubota (2013) e Pessoa e Urzêda-Freitas (2012) são importantes guias na criação de novos materiais para atividades e discussões críticas em sala de aula. Ferreira (2012) traz diversos exemplos de perguntas a serem feitas sobre imagens da mídia e que podem ser usadas para refletir sobre o racismo nelas imbuído. De igual modo, Kubota (2013) apresenta duas atividades que realizou com seus alunos no Canadá, motivando-os a pensar sobre o racismo na mídia daquele contexto. Pessoa e Urzêda-Freitas (2012), por sua vez, trazem três exemplos de planos de aulas para serem adaptados, todos envolvendo atividades de leitura: a primeira sobre corpo e preconceito, a segunda, prostituição, e a terceira, cultura, sexualidade e preconceito. Nesse sentido, é possível pensar para a sala de aula de línguas materiais didáticos que motivem o engajamento dos alunos para questionar criticamente questões de racismo em nossa sociedade.

Mais importante, contudo, é a tomada da consciência de que somos todos sujeitos ativos, através de nossas práticas discursivas, tanto na construção e manutenção de identidades quanto de injustiças que grupos de pessoas, fixadas em determinadas identidades, sofrem cotidianamente. Esta tomada de consciência deve ser o motor da prática de problematização constante desses discursos, na sala de aula e fora dela: uma tarefa inescusável para todos que desejam um Brasil mais verdadeiramente democrático. 


\section{Referências}

APPLE, M. Cultura e comércio do livro didático. In: APPLE, M. Trabalho docente e textos. Porto Alegre: Artes Médicas, 1995.

APPLE, M. Políticas de direita e branquidade: a presença ausente da raça nas reformas educacionais. In: Associação Nacional de Pós-Graduação e Pesquisa em Educação. Revista Brasileira de Educação, p. 61-7, 2001.

BERNARDINO, J. Ação afirmativa e a rediscussão do mito da democracia racial no Brasil. In: Revista estudos afro-asiáticos, ano 24, n. 2, p. 24773, 2002.

BOURDIEU, P. Language and symbolic power. Oxford: Polity, 1991.

BRASIL. Lei $\mathbf{n}^{\mathbf{0}} \mathbf{1 0 . 6 3 9}$, de 9 de janeiro de 2003.

BRASIL. Lei no 11.645, de 10 de março de 2008.

BRASIL. Ministério da Educação. Secretaria de Educação Média e Tecnológica. Parâmetros curriculares nacionais: ensino fundamental. Brasília: Ministério da Educação, 1998.

CAMARGO, M.; FERREIRA, A. de J. O racismo cordial no livro didático de língua inglesa aprovado pelo PNLD. In: Revista da ABPN, v. 6 n. 12, p. 177-202, 2014a.

CAMARGO, M.; FERREIRA, A. de J. Identidades sociais de raça no livro didático de língua inglesa: a branquitude como norma. In: FERREIRA, A. de J. (Org.) As políticas do livro didático e identidades sociais de raça, gênero, sexualidade e classe em livros didáticos. Campinas: Pontes Editores, p. 163-83, 2014b.

CARNEIRO, S. Movimento Negro no Brasil: novos e velhos desafios. In: Caderno CRH (Caderno do Centro de Recursos Humanos da Universidade Federal da Bahia), n. 36, p. 209-15, 2002. Disponível em: http://www.cadernocrh.ufba.br/. Acesso em julho/2015.

CAVALLEIRO, E. Do silêncio do lar ao silêncio escolar: racismo, discriminação e preconceito na educação infantil. São Paulo: Contexto, 2000 .

CERQUEIRA, D. R. C.; MOURA, R. L. de M. Vidas perdidas e racismo no Brasil. Brasília: IPEA, 2013.

FERREIRA, Formação de professores raça/etnia: reflexões e sugestões de materiais de ensino em português e inglês. Cascavel, PR: Coluna do Saber, 2006.

FERREIRA, A. de J. What has race/ethnicity got to do with EFL teaching? In: Linguagem \& Ensino, v. 10 n. 1, p. 211-33, 2007. 
FERREIRA, A. J. Identidades sociais, letramento visual e letramento crítico: imagens na mídia acerca de raça/etnia. Trabalhos em Linguística Aplicada (UNICAMP), v. 51, p. 193-215, 2012.

FREIRE, P. Pedagogia do oprimido. Rio de Janeiro: Paz e Terra, 1975.

GILLBORN, D. Racism and antiracism in real schools: theory, policy, practice. Buckingham: Open University Press, 1995.

GODOY, A. S. Introdução à pesquisa qualitativa e suas possibilidades. In: RAE artigos, São Paulo, v. 35, n. 2, p. 57-63, 1995.

GUIMARÃES, A. S. A. Racismo e anti-racismo no Brasil. In: Novos Estudos (CEBRAP), n. 43, p. 26-44, 1995.

HUGHES, J. The philosophy of social research. London: Longman, 1990.

KILLNER, M.; AMANCIO, R. Vontade de saber inglês. São Paulo: Editora FTD, 2012.

KUBOTA, R. Critical multiculturalism and second language education. In: NORTON, B.; TOOHEY, K. (Eds.) Critical pedagogies and language learning. Cambridge: Cambridge University Press, p. 30-52, 2004.

KUBOTA, R. Critical explorations of multiculturalism and race: language teacher reflecting on public events in the news. In: FIGUEREDO, C. J.; MASTRELLA-DE-ANDRADE, M. R. (Orgs.) Ensino de línguas na contemporaneidade: práticas de construção de identidades. Campinas: Pontes Editores, p. 129-50, 2013.

LEFFA, V. J. Identidade e aprendizagem de línguas. In: SILVA, K. A. da; DANIEL, F. de G.; KANEKO-MARQUES, S. M.; SALOMÃO, A. C. B. (Orgs.) A formação de professores de línguas: novos olhares. Volume II. Campinas: Pontes Editores, p. 51-81, 2012.

LUKE, A. Critical approaches to literacy. In: EDWARDS, V.; CORSON, D. (Eds.) Encyclopedia of language and education, v. 2, Dordrecht: Kluwer Academic Publishers, p. 143-52, 1997.

MASTRELLA, M. R. Inglês como língua estrangeira: entre o desejo do domínio e a luta contra a exclusão. Goiânia: UFG, 2007. Tese (Doutorado em Letras) - Faculdade de Letras da Universidade Federal de Goiás, Goiânia, 2007.

MASTRELLA-DE-ANDRADE, M. R. Pensando identidades em contextos de ensino-aprendizagem de línguas: uma discussão teórica introdutória. In: FIGUEREDO, C. J.; MASTRELLA-DE-ANDRADE, M. R. (Orgs.) Ensino de línguas na contemporaneidade: práticas de construção de identidades. Campinas: Pontes Editores, p. 17-60, 2013. 
MILES, R. Apropos the idea of 'race'... again. In: BACK, L.; SOLOMOS, J. (Eds.) Theories of race and racism: a reader. New York: Routledge, p. 125-43, 2001.

MOITA LOPES, L. P. Pesquisa interpretativista em linguística aplicada: a linguagem como condição e solução. In: D.E.L.T.A. v. 10, n. 2, p. 329-38, 1994.

NORTON, B. Identity and language learning: gender, ethnicity and educational change. Harlow: Longman, 2000.

NORTON, B. Identidade, letramento e ensino de línguas em diferentes partes do mundo. In: FIGUEREDO, C. J.; MASTRELLA-DE-ANDRADE, M. R. (Orgs.) Ensino de línguas na contemporaneidade: práticas de construção de identidades. Campinas: Pontes Editores, p. 89-108, 2013.

PENNYCOOK, A. Introduction: critical approaches to TESOL. TESOL Quarterly, v. 33, n. 3, Bloomington: Pantagraph Printing, p. 329-48, 1999.

PENNYCOOK, A. Critical applied linguistics: a critical introduction. New Jersey: Routledge, 2001.

PESSOA, R. R. A critical approach to the teaching of English: pedagogical and identity engagement. In: Revista Brasileira de Linguística Aplicada, v. 14, p. 353-72, 2014.

PESSOA, R. R.; URZÊDA-FREITAS, M. T. de. Ensino crítico de línguas estrangeiras. In: FIGUEIREDO, F. J. Q. de. (Org.) Formação de professores de línguas estrangeiras: princípios e práticas. Goiânia: UFG, p. 57-80, 2012.

ROSEMBERG, F.; BAZILLI, C.; SILVA, P. V. B. da. Racismo em livros didáticos brasileiros e seu combate: uma revisão da literatura. In: Educação e Pesquisa, São Paulo, v. 29, n. 1, p. 125-46, 2003.

SILVA, P. V. B. da; TEIXEIRA, R.; PACÍfICO, T. M. Programa de distribuição de livros didáticos e hierarquias raciais: o que dizem os alunos negros/as? In: FERREIRA, A. de J. (Org.) As políticas do livro didático e identidades sociais de raça, gênero, sexualidade e classe em livros didáticos. Campinas: Pontes Editores, p. 23-45, 2014.

WOODWARD, K. Identidade e diferença: uma introdução teórica e conceitual. In: SILVA, T. T. da; HALL, S.; WOODWARD, K. (Orgs.) Identidade e diferença: a perspectiva dos estudos culturais. Petrópolis, RJ: Editora Vozes, 2000. 